\title{
CONTROL OF THE CURRENT DENSITY PROFILE WITH LOWER HYBRD CURRIANT DRIVE ON PBX-M
}

\begin{abstract}
R. E. Bell, S. Bernabei, L. Blush, T. K. Chu, R. Doerner, J. Dunlap, d A. England, d G. Gettelfinger, N. Greenough, J. Harris, d R. Hatcher, S. Hirshman, d D. Ignat, R. Isler, ' S. Jardin, R. Kaita, S. Kaye, T. Kozub, H. Kugel, B. LeBlanc, S. Jones, J. Kesner, c D. Lee, d F. Levinton, ${ }^{\text {a }}$ S. Luckhardt, ${ }^{c}$ M. Okabayashi, F. Paoletti, ${ }^{c}$ S. Paul, F. Rimini, b N. Sauthoff, S. Sesnic, L. Schmitz, Y. Sun, H. Takahashi, W. Tighe, G. Tynan, E. Valeo, S. von Goeler
\end{abstract}

Princeton Plasma Physica Laboratory, Princeton University, P.O. Box 451, Princeton, NJ 08543 aFusion Physics and Technology, 3547 Vosager St, Suite 104, Torrance, CA 90503-1673

bJET Joint Undertaking, Abingdon Oxfordahire, OX143EA, United Kingdom

cMassachusetts Institute of Technology, 77 Massacirusetts Ave, Cambridge, MA 02139

dOak Ridge National Labaratory, Fusion Energy Division, P.O. B x 2009, Oak Ridge, TN $37831-8072$

Institute of Plasma and Fusion Research, University of California-Los Angeles, Los Angeles, CA 90024-1597

presented at the

Tenth TopicalConference on RADIO FREQUENCY POWER IN PLASMAS

April 1-3, 1993 in Boston, MA

preprint 


\title{
CONTROL OF THE CURRENT DENSITY PROFILE WITH LOWER HYBRD CURPANT DRIVE ON PBX-M
}

\author{
R. E. Bell, S. Bernabei, L. Blush, ${ }^{\bullet}$ T. K. Chu, R. Doerner, J. Dunlap, d \\ A. England, d G. Gettelfinger, N. Greenough, J. Harris, d R. Hatcher, S. Hirshman, d \\ D. Ignat, R. Isler, S. Jardin, R. Kaita, S. Kaye, T. Kozub, H. Kugel, B. LeBlanc, \\ S. Jones, ${ }^{c} J$. Kesner, ${ }^{c}$ D. Lee, d F. Levinton, ${ }^{\text {S }}$. Luckhardt, ${ }^{c}$ M. Okabayashi, \\ F. Paoletti, C S. Paul, F. Rimini,b N. Sauthoff, S. Sesnic, L. Schmitz, Y. Sun, \\ H. Takahashi, W. Tighe, G. Tynan, E. Valeo, S. von Goeler \\ Princeton Plasma Physics Laboratory, Princeton University, P.O. Box 451, Princeton, NJ 08543 \\ aFusion Physics and Technology, 3547 Voyager St., Suite 104, Torrance, CA 90503-1673 \\ bJET Joint Undertaking, Abingdon Oxfordshire, OX143EA, United Kingdom \\ 'Massachusetts Institute of Technology, 77 Massachusetts Ave., Cambridge, MA 02139 \\ dOak Ridge Nationul Laboratory, Fusion Energy Division, P. O. Box 2009, \\ Oak Ridge, TN $37831-8072$ \\ - Institute of Plasma and Fusion Research, University of California-Los Angeles, \\ Los Angeles, CA 90024-1597
}

\begin{abstract}
Lower hybrid current drive (LHCD) is being explored as a means to control the current density profile on PBX-M with the goal of raising the central safety factor $q(0)$ to values of 1.5-2 to facilitate access to a full-volume second stable regime. Initial experiments have been conducted with up to $400 \mathrm{~kW}$ of $4.6 \mathrm{GHz} \mathrm{LH}$ power in circular and indented plasmas with modest parameters. A tangential-viewing two-dimensional hard $x$-ray imaging diagnostic has been used to observe the bremsstrahlung emission from the suprathermal electrons generated during LHCD. Hollow hard x-ray images have indicated off-axis localization of the driven current. A serious obstacle to the control of the current density profile with LHCD is the concomitant generation of MHD activity, which can seriously degrade the confinement of suprathermal electrons. By combining neutral beam injection with LHCD, an MHD-free condition has been obtained where $\mathrm{q}(0)$ is raised above 1 .
\end{abstract}

\section{INTRODUCTION}

The Princeton Beta Experiment-Modified (PBX-M) is evaluating the use of lower hybrid current drive (LHCD) as a tool to alter the current density profile to improve confinement and stability. The operation of a tokamak reactor at a high plasma pressure (high $\beta$ ) is economically attractive. The PBX-M experiment is directed toward achieving high $\beta$ operation by accessing the second stable regime. ${ }^{1,2}$ Access to the second stable region was achieved in the outer portion of the PBX-M plasma with the use of high indentation to improve the magnetic well. 3 The requirements of high indentation are relaxed if the current density profile can be altered such that the safety factor, $q$, is raised in the plasma center. Obtaining $q(0)=1.5-2$ with suitably flat current density profiles near the edge are desired to place the full plasma volume in the second stable regime. 4

MHD activity can be altered by the introduction of $\mathrm{LH}$ driven current. Depending on the lower hybrid power, the waveguide phasing and the plasma density, MHD can be either stabilized or destabllized. LH induced MHD activity can seriously degrade the 
confinement of suprathermal electrons. This paper will examine the MHD activity during LHCD in circular and indented plasmas, with neutral beam injection (NBI) and without.

PBX-M is a medium sized tokamak with a major radius of $1.65 \mathrm{~m}$ and a minor radius of $0.3 \mathrm{~m}$ and is capable of plasma indentations up to $28 \% .^{3}$ The plasma is surrounded by a series of passive plates which make up a conducting shell to stabilize surface kink modes. The lower hybrid system on PBX-M operates at a frequency of 4.6 GHz. The coupler contains 32 waveguides each $6 \mathrm{~cm}$ high $\times 0.5 \mathrm{~cm}$ wide. The phase of each waveguide can be individually adjusted during the LH pulse (at a rate of $20 \% / \mathrm{ms}$ ). By adjusting the relative phases $(\Delta \downarrow)$ of the 32 waveguides, the parallel refractive index. $n\|=c k\| / \omega$, can be varied up to $n \|=4.1\left(\Delta \sigma=180^{\circ}\right)$. The coup er is located $8.7 \mathrm{~cm}$ below the midplane and is curved in two dimensions to approximate the edge contours of the plasma. A second coupler capable of a slightly higher $n \|$ spectrum will soon be added above the midplane.

Initial LH experiments 5,6 have been carried out at low LH power, $P_{L H} \leq 400 \mathrm{~kW}$. Consequently, plasmas with relatively low average electron density, $n_{e}=0.5 \cdot 3.0 \times$ $10^{19} \mathrm{~m}^{-3}$, electron temperature, $T_{e}(0)=0.8-1.2 \mathrm{keV}$, and plasma current, $I_{p}=100-250$ $\mathrm{kA}$, have been used to study the effects of LHCD. An $n \|=2.1\left(\Delta \|=-90^{\circ}\right)$ was used for the plasmas described in this paper. A tangential-viewing two dimensional hard $x$-ray (HXR) camera was constructed and installed on PBX-M to measure the bremsstrahlung emissions of the suprathermal electrons produced during LHCD. 7 Hard $x$-ray images with a $3 \mathrm{~ms}$ time resolution and a $3 \mathrm{~cm}$ spatial resolution allow the study of suprathermal production and confinement. Hard $x$-ray images have been correlated with MHD activity measured by a toroidal array of Mirnov coils and a soft $x$-ray (SXR) array. A Motional Stark Effect (MSE) diagnostic ${ }^{8}$ was used to measure changes in $q(r)$ during LHCD.

\section{LECD INTO CIRCULAR PLASMAS}

Many of the initial experiments with LHCD at low power were conducted with circular plasmas with relatively low electron density and plasma current. The low density improved the efficiency of current drive and the low current made it easier to study changes in the current density profile at low $P_{L H}$. At the lower densities, however, there was a tendency for the production of runaway electrons with LH when there was still a significant loop voltage present. Line average densities of $1.5-2 \times 10^{19}$ $\mathrm{m}^{-3}$ were sufficient to eliminate the runaway conditions.

Figure 1 shows some plasma parameters for a circular plasmas with and without LH power. With LHCD, the loop voltage $\left(V_{L O O P}\right)$ was reduced and large sawteeth were produced. The sawtooth inversion radius increased with the addition of LHCD, indicating that the radius of the $q=1$ surface was increasing. This was consistent with the damping of the $\mathrm{LH}$ waves inside the $q=1$ surface. The vertical HXR profile also showed a central peaking on axis.

Figure 2 shows the peaked HXR signal measured along a vertical chord of the image with a tangency radius near the plasma center plotted versus the time of each image. The measured $q$ profile from the MSE diagnostic for these plasmas is shown in Fig. 3. With LHCD, $q(0)$ was reduced as the $q=1$ radius increased. By comparing profiles from HXR and SXR measurements on the same vertical coordinates, some insight can be gained as to the location of the suprathermal population with respect to the MHD activity in the plasma. Plotted in Fig. 4 are the HXR profile and the amplitude of the $m=1$ sawteeth precursor oscillations as seen by the SXR array. The HXR intensity was peaked well inside the $q=1$ surface which occurred near the outer edge of the envelope of the $m=1$ precursor oscillations. For this circular plasma case (with $k=1$ ), this vertical position is in agreement with the radial q measurements from MSE $=15$ 

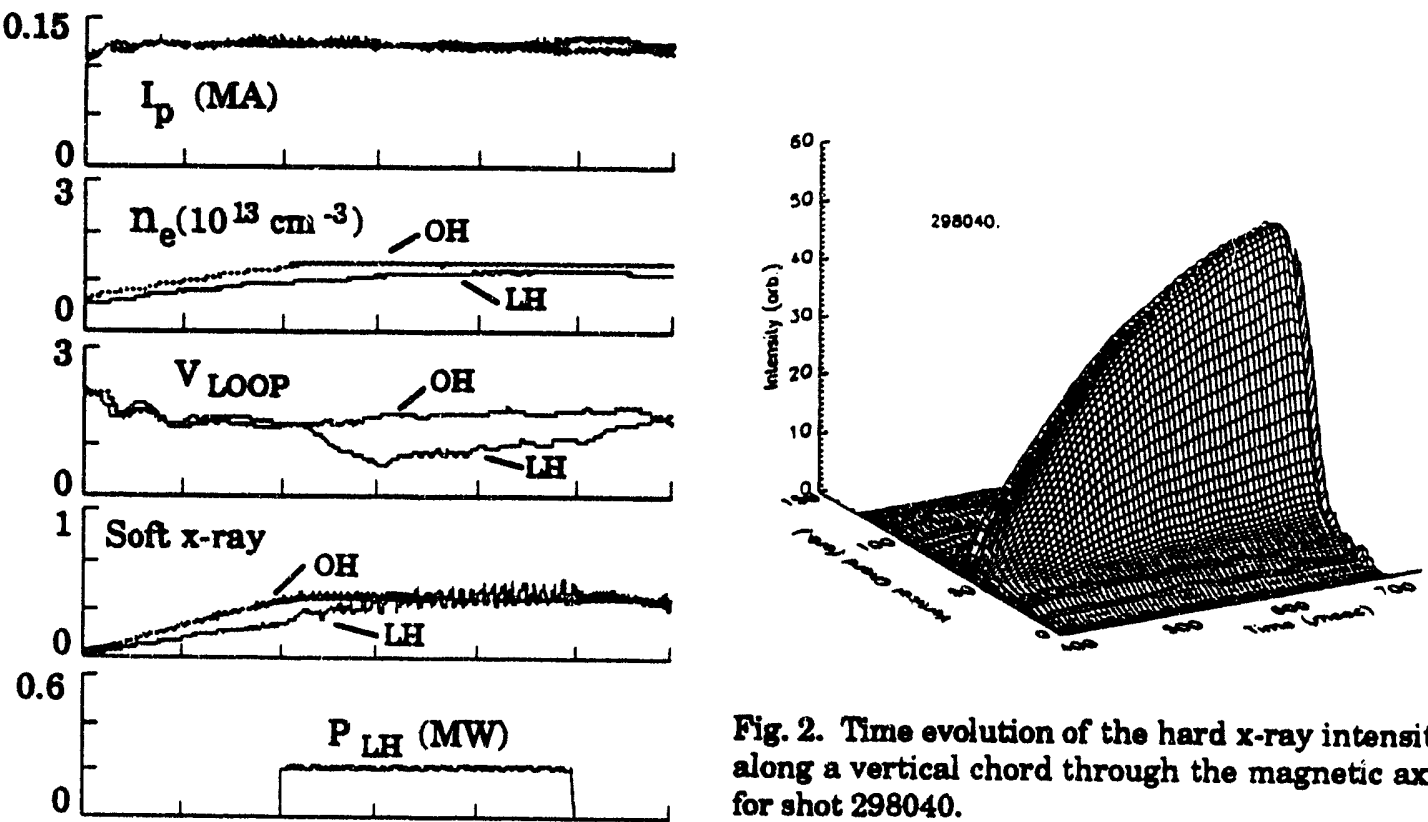

Fig. 2. Time evolution of the hard $x$-ray intensity along a vertical chord through the magnetic axis for shot 298040.
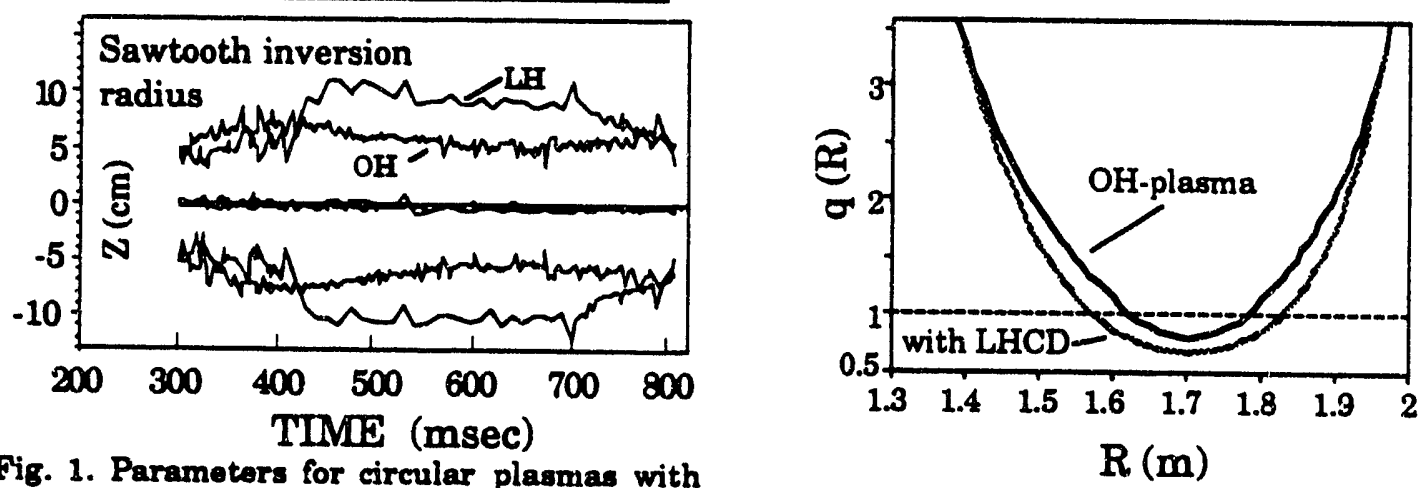

Fig. 3. Measured $q$ profile showing reduction of central q with LHCD into a circular plasma.

cm from center). When $q$ measurements are not available, such MHD activity can be used as a guide to the location of rational $q$ surfaces. In this way, with even elongated plasmas, MHD from the vertical SXR array can be compared along analogous vertical coordinates to vertical HXR profiles which are affected least by the line integration.

The large sawtooth amplitude and increasing sawtooth inversion radius are typical of LHCD into circular ohmic plasmas. For lower densities, a runaway condition would often develop with a greatly increasing hard $x$-ray intensity. Also, for higher LH power and/or lower density a large $n=1$ mode would frequently occur, which would eventually lock, and cause a disruption. The maximum electron density for these low current circular plasmas was limited, but this was overcome with the addition of neutral beam injection (NBI).

A small amount of NB power (0.5 MW) was added with a net LH power of $0.3 \mathrm{MW}$ to a circuiar discharge similar to the one shown above (with the timing of LHCD as above and coincident NBI) to increase the electron density of the plasma. As the density increased, the intensity of the HXR signal decreased as the efficiency of the LHCD was reduced (see Fig. 5). With the increase in density, the HXR profile was no longer peaked. Two distinct lobes appeared, and the distance between them increased as the profile became more hollow. Figure 6 shows contours of the HXR intensity along a vertical chord versus time and the peak positions of the lobes. 


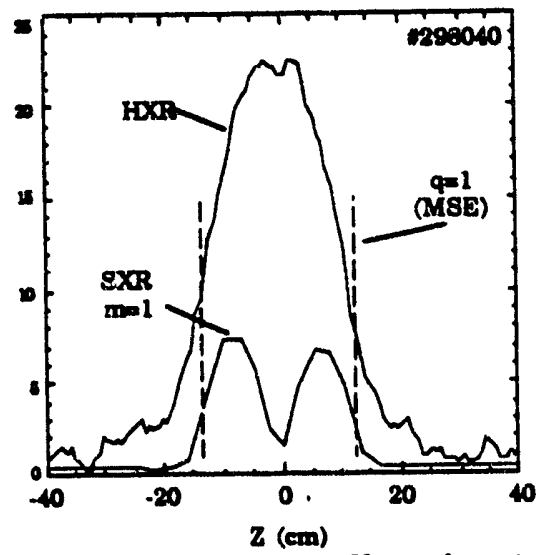

Fig. 4. Hard $x$-ray profile and $m=1$ oscillations from the SXR array versus vertical position with appraximate $q=1$ radius from MSE.

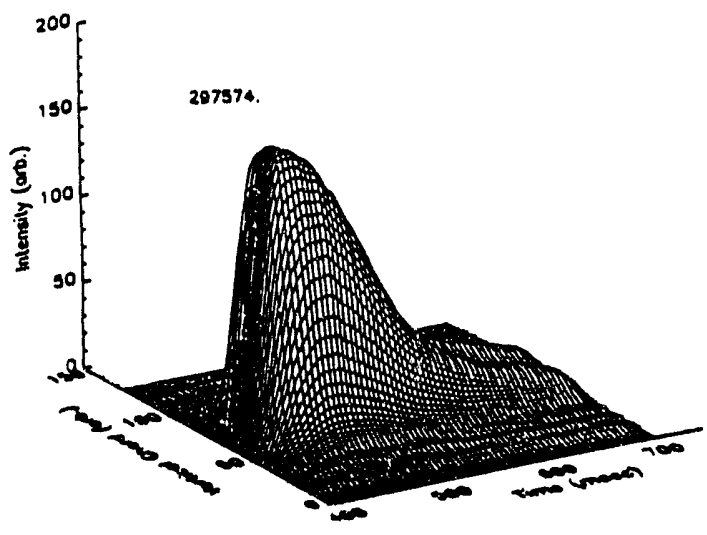

Fig. 5. Time evolution of hard $x$-ray intensity for circular plasma with LHCD and NBI .

It is useful to quantify this "hollowness" with a parameter that takes into account the shape and depth of the central region with respect to the width of the profile. The parameter for hollowness used here has a value of -1 for a centrally peaked parabolic profile, 0 for a flat central region, and positive values for increasing hollowness. Figure 7 shows this hollowness parameter increasing with electron density. Normalized HXR profiles are shown in Fig. 8 at an early and late time to illustrate the degree of hollowness that is represented by the quantity plotted in Fig. 7. This hollowness parameter can reflect changes in the HXR profile which are often brought about by MHD activity. A decreasing hollowness is often an indication of an increasing diffusion of the suprathermal electrons. It could also indicate a change in LH absorption or the creation of runaway electrons. The large sawteeth which can be seen on the line averaged electron density in Fig. 7 have an effect on the suprathermal distribution. At each sawtooth event, a corresponding drop in the hollowness parameter can be seen. The sawteeth, while momentarily decreasing the hollowness, do not impede a rising trend in hollowness.

The effect on the HXR profile during a sawtooth cycle is shown in Fig. 9. Just after a sawtooth crash, the HXR profile was generally flat in the central region. As the cycle proceeded with the corresponding increases in

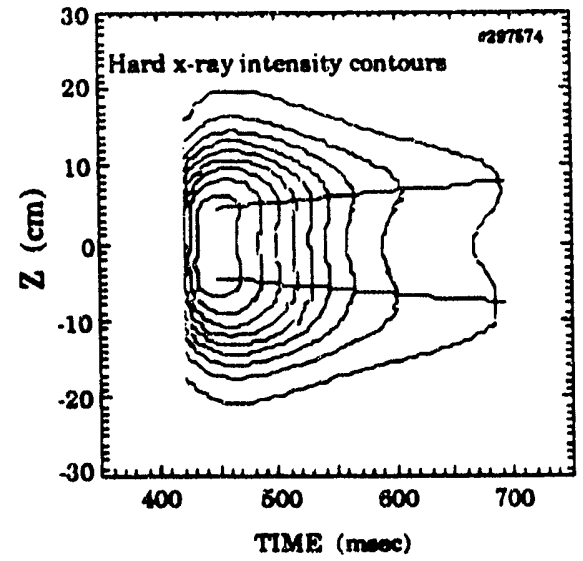

Fig. 6. Contours of hard x-ray intensity. Lines indicate position of maximum values at each time slice.

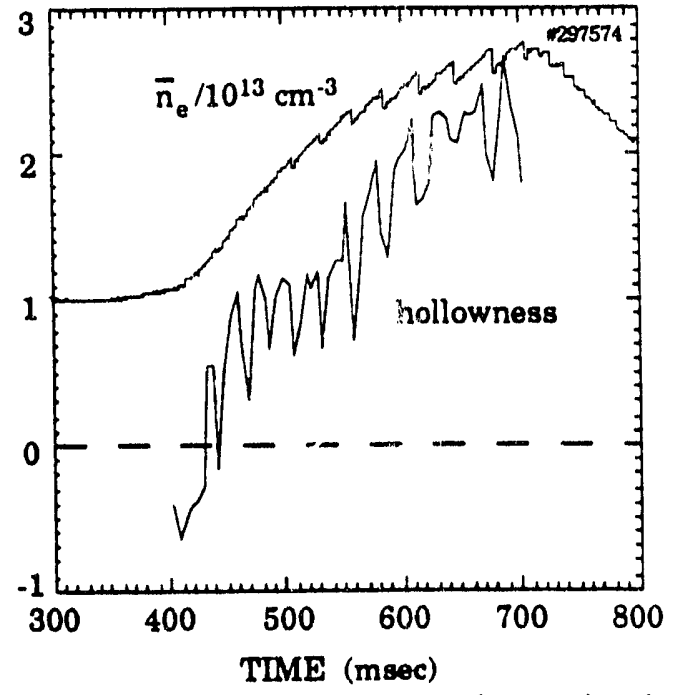

Fig. 7. Hollowness parameter increasing in time with electron density. A decrease in hollowness occurs at each sawtooth crash. 


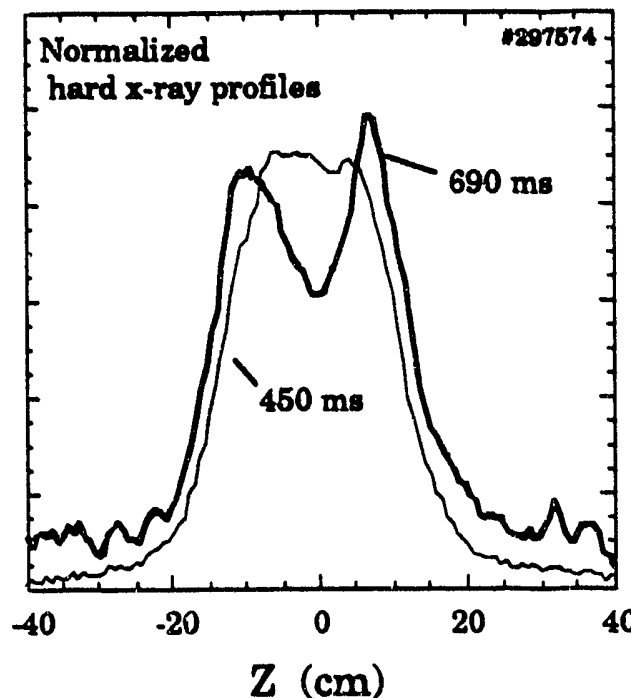

Fig. 8. Normalized HXR profiles early and late during the LHCD pulse showing increasing hollowness. electron density and temperature, the hollowness increased. This was seen as a reduction in the HXR intensity in the central portion of the profile. This hollowing out of the central region may indicate that the diffusion of suprathermals into this region was reduced during the period between sawtooth crashes or a changing LH absorption. At the sawtooth crash the lobes of the profile were eliminated; the reconnection of the magnetic field lines were adversely affecting the confinement of the suprathermal electrons.

If the fast electron diffusion was small, the position of the lobes on the HXR profile (or just outside the lobes due to the chord averaging), should be approximately the location where the suprathermal production was occurring, i.e. where current was being driven by LH. In the first example of LHCD in a circular discharge, no hollowness was seen, and a central peaking was consistent with the large sawteeth amplitude, the increased sawtooth inversion radius, and LH current deposition within the $q=1$ surface. In the second example with $\mathrm{NBI}$ and higher density, two distinct lobes appeared which moved outward as the density increased. In the latter case, the sawtooth amplitude also increased suggesting that LH current was still being deposited inside the $q=1$ surface. Soft $x$-ray data were not available for these LHCD plus NBI plasmas, but the sawtooth inversion radius, and therefore the $q=1$ surface, could be estimated from Thomson scattering profiles. The position of the HXR lobes were within this radius. The expanding lobe position is probably reflecting the accessibility of the LH wave into the central region of the plasma. At higher central densities, the $\mathrm{LH}$ wave does not reach the center and damps off axis but still within the $q=1$ surface.

\section{LHCD INTO INDENTED PLASMAS}

By shaping the plasma, higher values of plasma current and electron density can routinely be reached. For LHCD experiments plasmas with indentations from $10-14 \%$ and plasma currents in the range $180-250 \mathrm{kA}$ were typical. Hollow HXR profiles were common, but a variety of MHD modes could be destabilized by LHCD often resulting in a reduction in hollowness or a loss of suprathermal electrons measured as a loss in HXR intensity.

The dominant MHD modes were $m=1 / n=1$, $m=3 / n=2$ together with $m=2 / n=2$, and $m=2 / n=1$. The toroidal mode number, $n$, was determined from a toroidal array of Mirnov loops. The poloidal mode
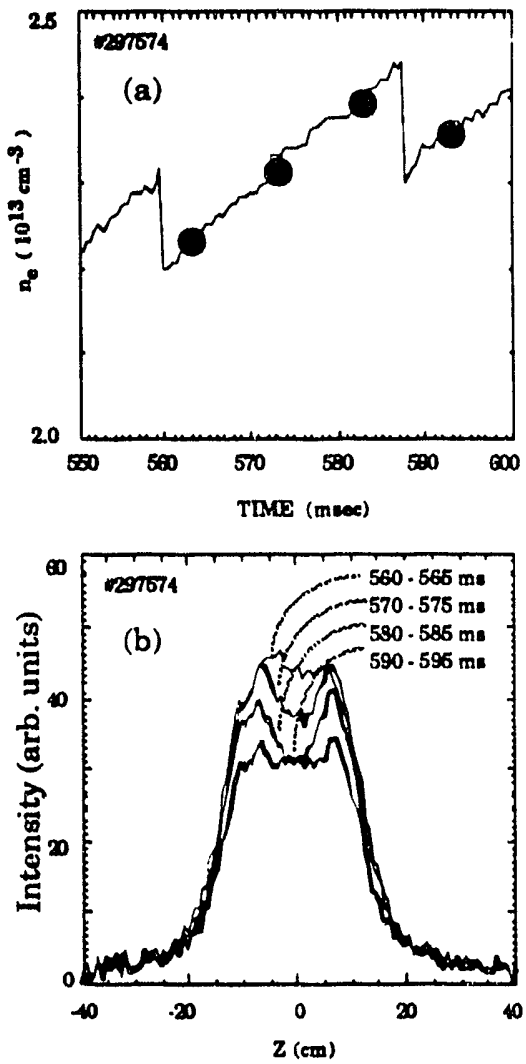

Fig. 9. (a) Line average electron density with sawtooth signature.

(b) Evolution of HXR profile during a sawtooth cycle in circular plasma with LHCD and NBI. 
number, $m$, was determined from the $S X R$ array. For all MHD modes observed, the hollowness of the HXR profile could be adversely affected when the modes had sufficient amplitude. An $m=2 / n=1$ mode coupled to a $m=1 / n=1$ mode could destroy suprathermal confinement as indicated by a sudden drop in HXR intensity. These coupled modes would often lock causing a disruption. With LH current deposition inside of the $q=1$ surface, MHD activity would often be seen to increase. Tith the LH current deposition outside of the $q=1$ surface and sufficient $L H$ current, the $q=1$ radius was observed to decrease.

Two cases with LH current deposition outside of the $q=1$ surface will be considered here with $\mathrm{I}_{\mathrm{p}}=180 \mathrm{kA}, q_{\text {edge }}=8, \mathrm{k}=1.7$, and an indentation of $12 \%$. The first case had LHCD alone and the second case had LHCD plus NBI. The time evolution of the HXR intensities for these two cases are shown in Fig. 10 (LHCD) and Fig. 11 (LHCD + NBI). In both cases, the $q=1$ radius decreased with the application of LHCD.

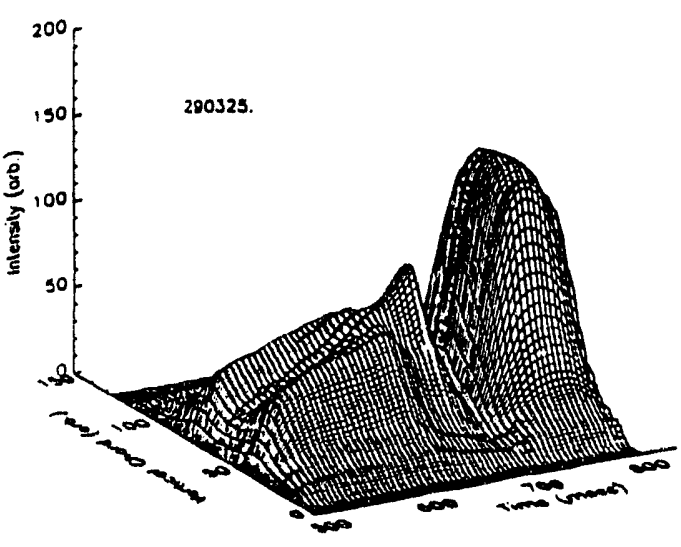

Fig. 10. Time evolution of hard $x$-ray intensity for indented plasma with LHCD.

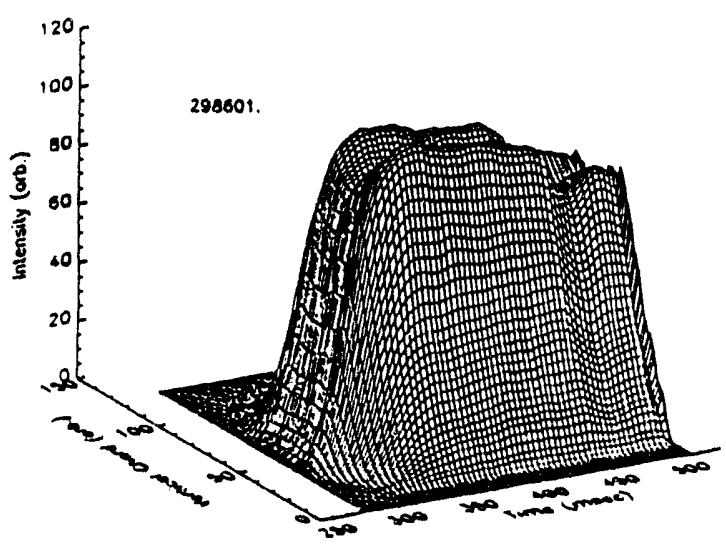

Fig. 11 Time evolution of hard x-ray intensity for indented plasma with LHCD and NBI

For the first case of Fig. 10, a net LH power of $360 \mathrm{~kW}$ was applied to a plasma with a line averaged density of $2.2 \times 10^{19} \mathrm{~m}^{-3}$. Some parameters for this discharge are shown in Fig. 12. Shown are the line-averaged electron density, a central SXR signal, loop voltage, the hollowness parameter from the HXR image, and a Mirnov signal.

Contours of the amplitude of the oscillations measured with the SXR array between 4 and $8 \mathrm{kHz}$ can be seen at the bottom of Fig. 12. Both $m=1$ sawteeth precursors and bursts of $m=1$ oscillations are present. The radius of the $q=1$ surface as indicated by these oscillations decreased in time after the application of LHCD. The last sawtooth event occurred at $625 \mathrm{~ms}$. With the disappearance of all $\mathrm{m}=1$ activity at about $635 \mathrm{~ms}$, an $\mathrm{m}=2$ mode began to grow. At about this time the $q=1$ surface is believed to have disappeared. The $m=2 / n=1$ mode increased in amplitude leading to a disruption at $700 \mathrm{~ms}$. This $m=2 / n=1$ mode may have been destabilized due to $L H$ current deposition near the $q=2$ surface or perhaps more indirectly through change in the $q$ profile in which $q^{\prime}$ was flattened near $q=2$. Figure 13 shows the HXR profiles and SXR MHD amplitudes for the $\mathrm{m}=1$ mode at $600 \mathrm{~ms}$ and the $\mathrm{m}=2$ mode at $650 \mathrm{~ms}$. The lobe position was outside of the $m=1$ position consistent with deposition of $L H$ current outside of the radius of $q=1$.

As the $m=2 / n=1$ mode grew, there was a peaking and a narrowing of the HXR profile which can be seen in the contours of HXR intensity and in the hollowness parameter of Fig. 12. The drop in HXR intensity at the location of the $m=2$ island indicates a loss of suprathermal confinement (see Fig. 12 center and Fig. 13). The subsequent disruption may have resulted from the change in the $q$ profile asssiciated with the loss of the current-carrying suprathermal population due to the $m=2$ morie. The large HXR signal after the disruption in Fig. 10 was due to a runaway condition because of the low electron density. 


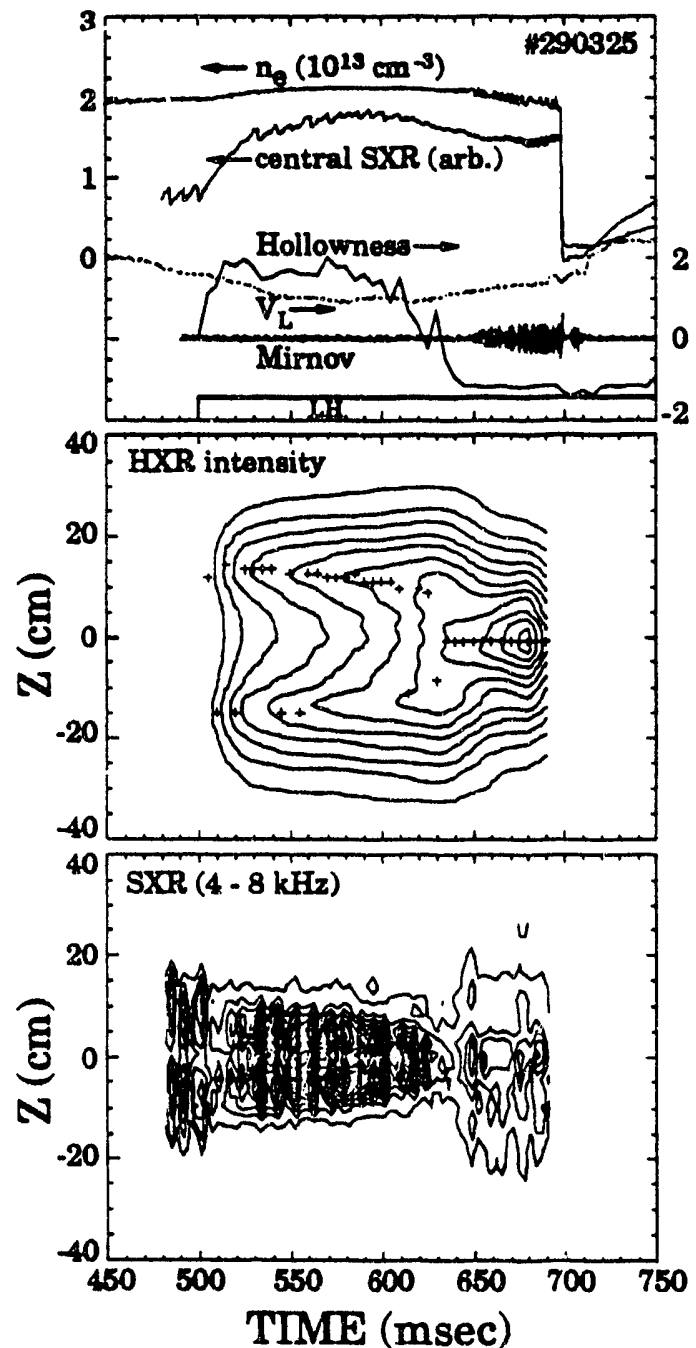

Fig. 12. LHCD into indented plasma.

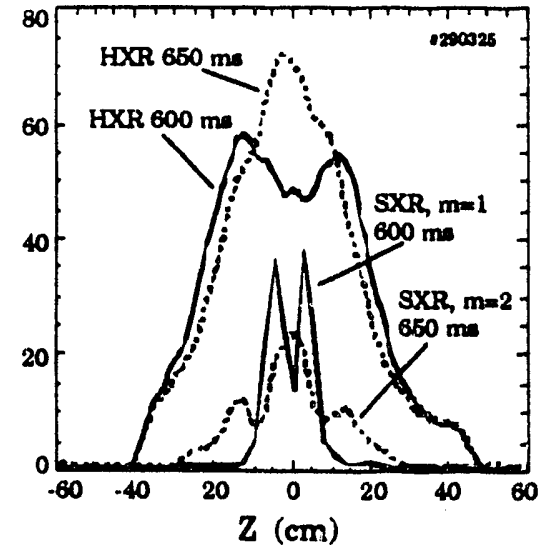

Fig. 13. Comparison of HXR profiles and SXR MHD amplitudes during $L H C D$.
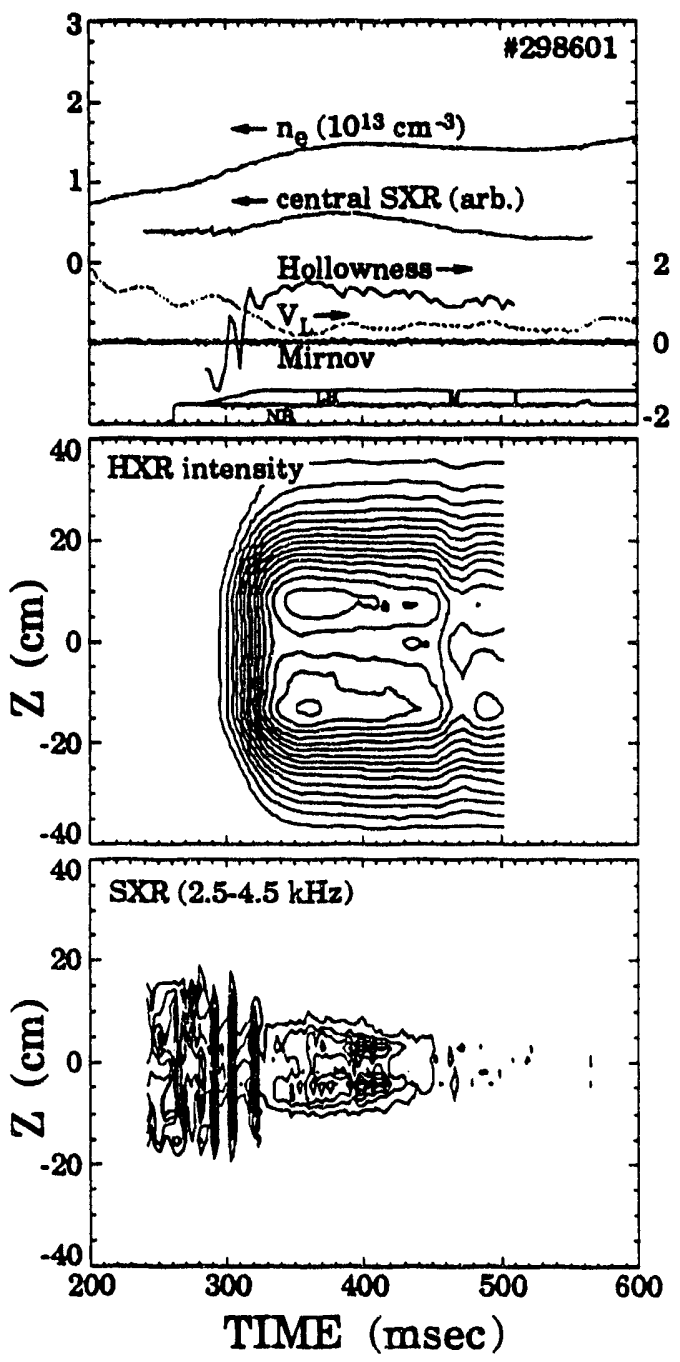

Fig. 14. LHCD plus NBI into indented plasma.

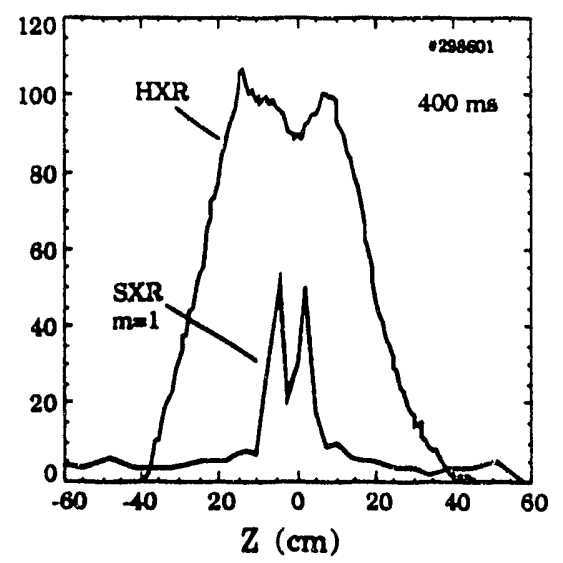

Fig. 15. Comparison of HXR profile and $m=1$ during LHCD plus NBI. 
Even before the onset of the $m=2 / n=1$ mode, there is a gradual reduction in the hollowness of the HXR profile. The central region of the HXR profile was observed to fill in and become peaked. The reason for this is unclear. There was ongoing sawteeth and $m=1$ activity during this time, as before, and the $q=1$ surface was shrinking. This seems to be analogous to the behavior of the HXR profile during sawteeth for the circular plasma described above. The filling in of the HXR profile, just in the central region, seems to indicate that the suprathermal confinement (or the LH damping) was affected by the reconnection process occuring at the sawtooth crash.

For the case shown in Fig. 11, the addition of small amount of NBI power to LHCD resulted in an MHD-free discharge. Shown in Fig. 14 are parameters from a discharge with a net LH power of $334 \mathrm{~kW}, 0.56 \mathrm{MW}$ of NBI and a line averaged density of $1.5 \times$ $10^{19} \mathrm{~m}^{-3}$. NBI was begun early in the discharge, and sawteeth were quickly suppressed as the LH power was ramped up. An $m=1$ oscillation remained for another $120 \mathrm{~ms}$ until it too disappeared, after which no MHD were present. Figure 15 shows the HXR profile at $400 \mathrm{~ms}$ compared to the location of the $m=1$ mode which was still present at that time. The MHD-free condition was maintained until the end of the LHCD and NBI period at $750 \mathrm{~ms}$. The decreasing radius of the $m=1$ mode (see bottom of Fig. 14) with constant $I_{p}$ indicates a broadening of the current profile. A measurement of the q profile with MSE for this discharge indicated that $q(0)$ rose above 1 by $t=530 \mathrm{~ms}$. It is not yet understood what role NBI plays in suppressing MHD modes that are present with LHCD alone. An increase in electron temperature affecting wave damping or a change in the shear due to NB driven current are possible explanations for the observed improvement.

The HXR intensity remained relatively constant and a hollow profile was maintained. The position of the lobes of the HXR profile remained unchanged as the radius of the $q=1$ surface was decreasing, suggesting that the location of LH current deposition also remained constant.

In summary, the HXK images from suprathermal electrons produced during LHCD have been correlated । rith MHD activity in PBX-M. In particular, the lociation of the LH current deposition correlates with observed changes in the $q$ profile. The effect of the sawtooth crash on the HXR profile indicate that the reconnection process affects suprathermal confinement. MHD modes can be induced by LHCD, and can adversely affect suprathermal confinement. The addition of NBI to LHCD can suppress low $n$ modes that otherwise would destroy localization of LH current.

This work was supported by U.S. Dept. of Energy, Contract Nos. DE-AC02-76-CH03073 (PPPL), DE-AC05-84OR21400 (ORNL), DE-FG02-91ER54109 (MIT), and DE-FG0289ER51121(UCLA).

\section{REFERENCES}

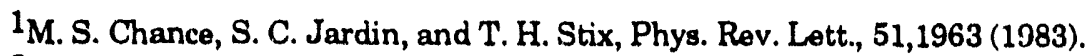

${ }^{2}$ R.C. Grimm, M. S. Chance, A. M. M. Todd, et al.,Nucl. Fusion, 25, 805(1985).

${ }^{3}$ R. E. Bell, N. Asakura, S. Bernabei, et al., Phys. Fluids B 2, 1271 (1990).

$4_{M}$ M. S. Chance, Y.-C. Sun, S. C. Jardin, C. E. Kessel, and M. Okabayashi, Proceedings of the Second Symposium on Plasma Dynamics:Theory and Applications, University of Trieste, Italy (July 8-10, 1992).

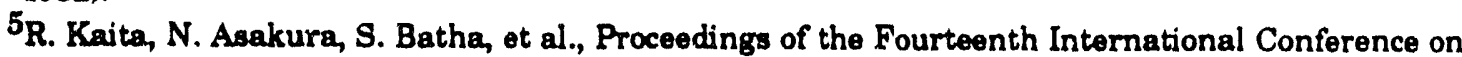
Plasma Physics and Controlled Nuclear Fusion Research, (Wurzburg, Germany, September 1992)(International Atomic Energy Agency, Vienna, Austria, Paper IAEA-CN-56/H-1-2.

6S. Bernabei, R. Bell, M. Chance, et al., Phys. Fluids B, in press.

7S. von Goeler, N. Asakura, R. Bell,et al., in Plasma Physics and Controlled Nuclear Fusion Research, Proceedings of 18th European Conference, Innsbruck, Austria, 1992, (European Physical Society, Ceneva, 1991), Vol. II, 949.

${ }^{8}$ F. Levinton, R. J. Fonck, G. M. Gammel, R. Kaita, H. W. Kugel, E. T. Powell, and D. W. Roberts, Phys. Rov. Lett., 63, 2060 (1989). 
Dr. F. Pesloni, Univ. of Wollongong. AUSTRALIA

Prot. M.H. Brennan, Univ. of Sydnoy. AUSTRALIA Plasma Research Lab., Australian Nac Univ., AUSTRALIA

Prof. I.R. Jones, Finders Univ, AUSTRALIA

Prof. F. Cap. Inst for Theoretical Physics. AUSTRIA

Prot. M. Heindtor, Instiut for Theoresischo Physik, AUSTRIA

Prof. M. Goossens, Astronomisch InstituUt, BELGIUM

Ecole Royalo Nituire, Leb. do Phy. Plaemas, BELGIUM

Commission-Europen, DG. XII-FUsion Prog., BELGIUM

Prof. R. Bouciqub, Rijkeuniverileit Gent, BELGIUM

Dr. P.H. Sakenaka, Instibto Firica, BRLZIL

Instituto Meciond Do Pesquiens Especicis-INPE, BRAZIL

Documents Ofirce, Abmic Enorgy of Conada Ld., CANADA

Or. MP. Bectynekx. MPB Tecthnologios, Ine., CANADA

Dr. H.M. Skaregard, Univ. of Sackatchowen, CANADA

Prot. J. Teichmem, Univ. of Montrad, CANADA

Prof. S.R. Sreenivesen, Univ. of Calgary, CANADA

Prof. T.W. Jometon, INRSEnergie, CANADA

Dr. R. Botton, Contro canadien de husion magnótique, CANADA

Or. C.R James.. Univ. of Nbera. CANADA

Dr. P. Lukte, Komensketho Universate, CZECHOSLOVAKIA

The Librarian, Cuham Leboratory. ENGLAND

Librey, R61, Ruthertord Applaton Laboratory. ENGLAND

Mrs. S.A. Huthinason, JET Librey, ENGLAND

Dr. S.C. Sheme, Univ. of South Pacific. FIJI ISLANDS

P. Mahonen, Univ. of Holsinki, FINLAND

Prot. M.N. Buseac. Ecoto Polytechnique, FRANCE

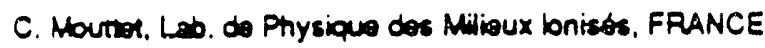

J. Radal CENCAOARACHE - Bat 506, FRANCE

Prot. E. Economou, Univ. of Creto, GREECE

Ms. C. Rinri, Univ. Jf loamina, GREECE

Dr. T. Mul, Acadormy Bibliographic Ser., HONG KONG

Proprint Library, Hungarian Acadomy of Sai., HUNGARY

Dr. B. DasGupte, Saha Inst of Nuctoer Physics, INDIA

Dr. P. Kaw, Inst. for Plasma Rosearch, INDIA

Dr. P. Rocenes, lered Inst of Technology, ISPAEL

Librarien, Intemabiond Conter for Theo Physics, ITALY

Miss C. Do 'ab, Associaziono EURATOAENEA, ITALY

Dr. G. Grosso, Istruto a Fisica del Plasma, ITALY

Prof. G. Rostangni, Istruto Gas lonizzat Dol Cnr, ITALY

Or. H. Yamato, Toeniba Res Dovet Center, JAPAN
Prof. I. Kawakemi, Hiroshima Univ., JAPAN

Prof. K Nishikawa, Hiroshima Univ., JAPAN

Director, Japan Atomic Energy Research Inst, JAPAN

Prof. S. IDh, Kyushu Univ., JAPAN

Pesearch Into. Cr., National Instit for Fusion Science. JAPAN

Prot. S. Tanake, Kyoso Univ., JAPAN

Librey, Kyoto Univ., JAPAN

Prof. N. Inow, Univ. of Tokyo, JAPAN

Secretary, Plasma Section, Electorochnical Lab., JAPAN

S. Mori, Tectrical Advieor, LAEPI, MAPANi

D. O. Mitera, Kumemow Inst of Technology. JAPAN

J. Hycon-Sook, Korve Abomic Energy Research Inst, KOREA

D.I. Choi, The Korea Adv. Inst of Sai. \& Tech., KOREA

Prot. 8.S. Liby, Univ. of Waikat. NEW ZEALAND

Into of Phycica, Chinese Acad Sa PEOPLE'S REP. OF CHINA

Lurery, Inst of Plasma Physics, PEOPLE'S REP. OF CHINA

Tringhua Univ. Library, PEOPLE'S REPUBLIC OF CHINA

Z. Li, S.W. Inst Physics, PEOPLE'S REPUBUC OF CHINA

Prof. J.A.C. Cebra, Instuto Superior Tecnico. POATUGAL

Dr. O. Potrus, Al I CUZA Univ., ROAMANIA

Dr. J. Villiors, Fusion Studios, AEC. S. AFPICA

Prof. M.A. Helberg. Univ. of Natu, S. AFRICA

Prof. D.E. Kim, Pohang Inst. of Sci. \& Tech., SO. KOREA

Prof. C.I.E.MA.T, Fusion Division Library, SPAIN

Dr. L Swonfio, Univ. of UMEA, SWEDEN

Librery, Royed inst of Technology, SWEDEN

Prof. H. Whot nson, Chalmers Univ. of Tech., SWEDEN

Contro Phys. Des Plasmas, Ecole Polytech, SWITZERLAND

Bibliothed, Inst. Voor Plasma-Fysica, THE NETHEFLANOS

Asst. Prot. Dr. S. Cakir, Nidde East Tech. Univ., TURKEY

Dr. VA. Gulhtikn,Sai. Res. Inst Electrophys.l Apparatus, USSR

Dr. D.D. Pyubv, Siberian Branch of Academy of Sa.. USSR

Or. GA. Eisoov, I.V. Kurchator Inst, USSR

Ubrarion, The Ukr.SSR Acadomy of Scionces, USSR

D. LM. Kovriztnykh, Inst. of General Physias. USSA

Kentorectungeaniege GmoH, Zontralbibliothek. W. GERMANY

Bibliothot Inst for Pbamatorsctiung, W. GERMANY

Prof. K. Schinder, Ruhr-Universita Boctum, W. GERMANY

Dr. F. Wagner. (ASOEX), Max-Planck-Instouth W. GERMANY

Lorarian, Max-Plenck-Insturt, W. GERMANY

Prot. A.K dener, Inst of Physics, YUGOSLAVIA 

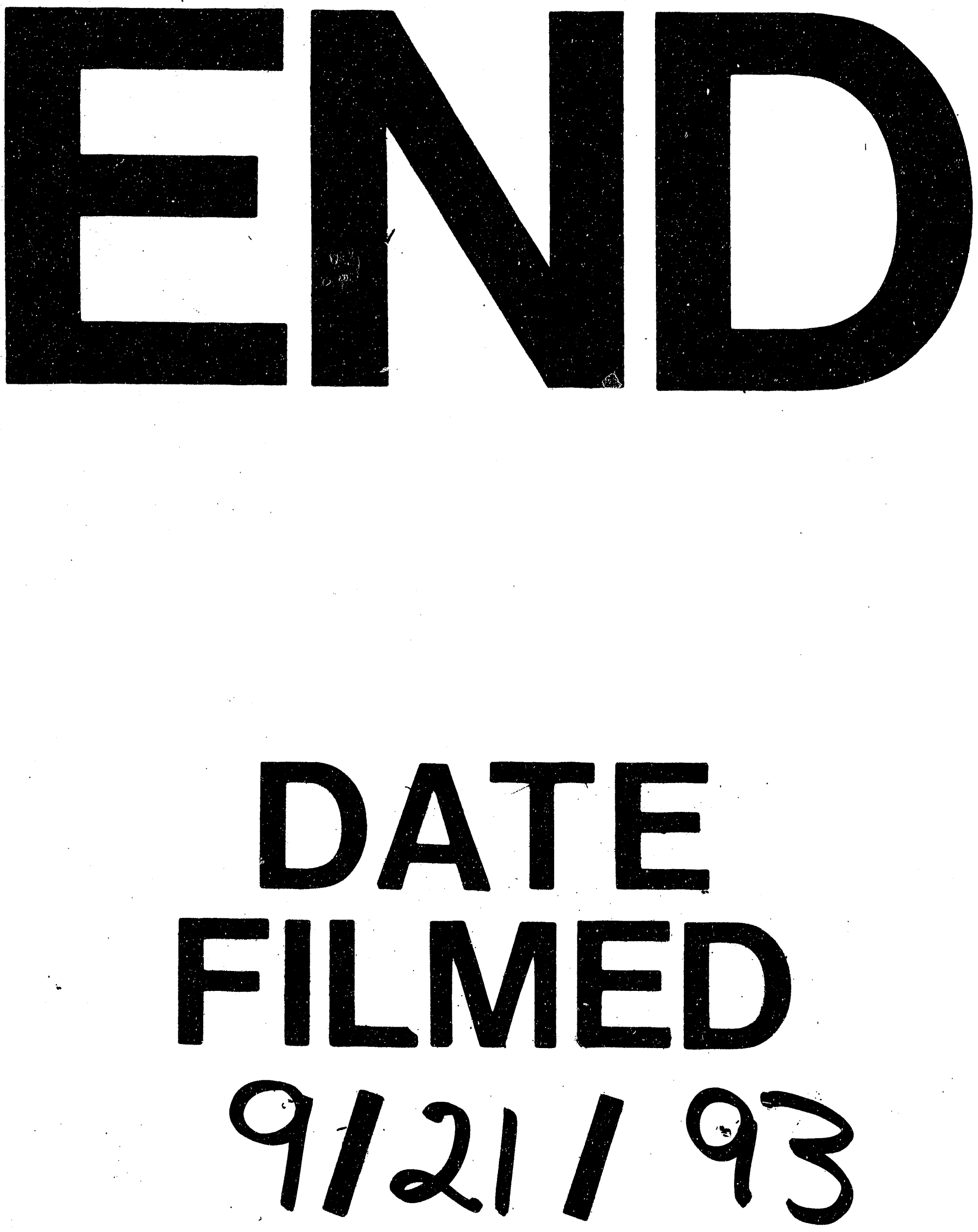

1 
